\title{
Research on the Transaction Cost of the Reform of State-Owned Enterprises
}

\author{
Fan Dong, Xuefeng Zheng \\ School of Government, Beijing Normal University, Beijing, China
}

Keywords: Transaction costs; State-owned enterprise; enterprise; Power supply.

\begin{abstract}
From the perspective of transaction cost of new institutional economics, the benefits of enterprises in market trading are studied. But state-owned enterprises with government nature have not only brought benefits but also brought costs. Therefore, this paper argues that the existence of state-owned enterprises is inevitable from the perspective of transaction cost, and the inevitable result of state-owned enterprises' participation in market competition and the reform of state-owned enterprises.
\end{abstract}

\section{The optimal allocation of resources is the ultimate goal of any economic system and economy.}

We assume that an economy or an economic system is a free market economy, according to Sir Arthur salter's description of the economic system as selected by kos: "the normal economic system works itself. There is no central control or central check. For all the range of human activities and human needs, supply is adjusted according to demand, and production is adjusted according to consumption, which is automatic, flexible and responsive. The orderly operation of the specific system, the optimal allocation of resources and the flow direction depend on certain mechanism. The resource allocation of the economic system that coase selected is dependent on the price mechanism, but coase also believes there is a command mechanism (organization). Therefore, the orderly operation mechanism of a particular system includes price mechanism and organization mechanism (command). As shown in the figure:

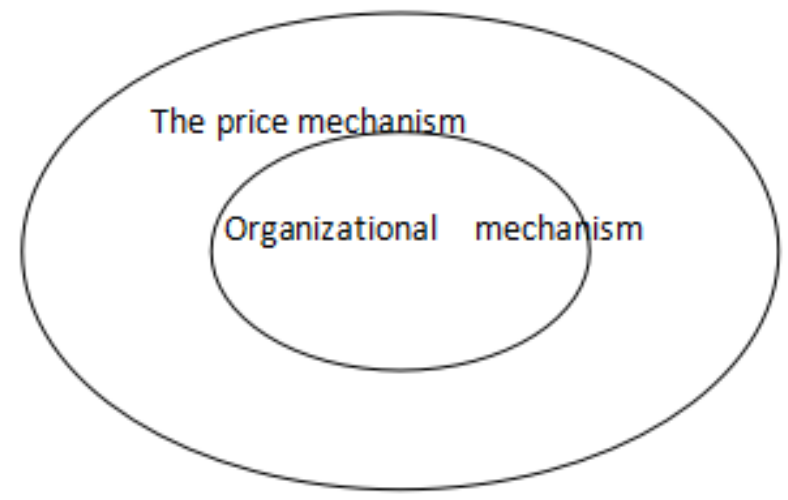

Is the cause of the price mechanism works market transaction price decision: "price movements decided to production, this is done through a series of market transactions to coordinate", group work is the cause of the market transaction cancelled, business owners command: "within enterprises, the market transaction cancelled, along with alternative trading in the complex market structure times entrepreneurs, entrepreneurs directing production."

Therefore, in the market transaction (resource allocation), there are two mechanisms: "the allocation of resources is determined by the price mechanism; Another is the resource allocation that has been associated with the entrepreneur of the coordinator. Among them, the price mechanism is the basic mechanism of resource allocation, the organization mechanism is the derivation mechanism of resource allocation and the alternative method of price mechanism (substitute). The order and proportion of these two mechanisms in different countries depends on different countries. 
This article preliminary discussion from the perspective of enterprise in state-owned enterprises exist, from the market transaction exists necessity to understand the inevitability of state-owned enterprises to participate in market competition, from the perspective of government cost necessity to understand the necessity of the reform of state-owned enterprises.

\section{Understand the Inevitability Of State-Owned Enterprises From The Perspective Of Enterprise Emergence}

The price mechanism is the basic mechanism of resource allocation, the organization mechanism is the derivation mechanism of resource allocation and the alternative method of price mechanism (substitute). As an alternative mechanism, the organizational mechanism can be the enterprise or the government (special enterprises). This paper starts with the enterprise and then discusses the government.

What is an enterprise? "When the orientation of resources is dependent on entrepreneurs, businesses that are formed by a number of relational systems are starting to emerge," says Mr Coase. So why does resource orientation depend on entrepreneurs? What are some relational systems?

The resource allocation in the market is mediated by price mechanism, but the market operation is cost.

First, the price mechanism is found to be cost, which is to find the relative price work. "For all individuals, all relative prices are known", which is an assumption of static theory. But this is clearly not the reality of the real world. (P3) costs can be reduced with the presence of people who specialize in this work, but cannot be eliminated. At the same time, in order to reduce or reduce the cost, a production factor owners will assume a mechanism can not to this kind of cost, namely cooperation or an organization, personnel in the cooperation between people or organizations in order to obtain a certain reward, which could be fixed or floating) agreed within limits to obey production factor owners command. At the same time, the contract between each other is limited to the scope of power of the owner of the production factor (entrepreneur), which is to be subject to the command within this scope. Once this contract is reached, the person or organization within the organization does not need to pay the cost. If you have to pay the cost (externally), then you have to pay a cost, "a series of contracts is replaced by a contract". When the organization learned about the price mechanism, others could share it, thus saving the cost. Therefore, organizations (enterprises) are established to reduce costs by reducing the cost of discovering price mechanisms, signing fees and negotiating fees.

Second, the future uncertainty created by a short-term contract and the need for short-term contracts to make frequent contracts increase the cost of contracts. Market transactions, the supply of some items, especially the supply of labor, "if signed a long-term contract instead of a number of short-term contract", so, a frequent sign can reduce the cost of short-term contracts. However, due to the uncertainty of the information itself and the technical uncertainty of predicting the future information, there will be a lot of uncertainty about the future forecast of the production itself or the external environment. Among them, the buyer to avoid waste of cost, not explicitly ask for specific actions, related articles, especially the labor contract should not be too long, even with a long-term contract can be signed, but the supplier to provide goods or services in the future only in general terms, and the specific details for the buyer need clear again and again. When the flow of resources (especially Labour) depends on the buyer, "the relationship of 'business' becomes popular" (P4). Therefore, establishment of organization (enterprise) is to cope with uncertainty, information suppliers and demanders consultation (mostly) at demanders will, through long-term contract implementation resources (labor), in the form of configuration.

Thirdly, government supervision, taxation and other management measures will be conducted on market transactions. In order to reduce the cost and constraints of government regulation, an organization (enterprise) will emerge in a specialized exchange economy. Even if the government has some requirements within the organization (enterprise), there will be some cost, but it will be much lower than the government supervision, taxation and other management measures. What's more, some of the government's management measures are focused on market trading rather than on organizations. 
Therefore, by the price mechanism to adjust the allocation of resources in a professional in the market economy, when resources depends on the guidance of the entrepreneur, there are some relationship between system structure of the organization (enterprise) began to appear.

\section{The Necessity to Understand The Market Competition Is Inevitable}

The existence of the organization (enterprise) is due to the existence of the market operation cost, and it can eliminate certain costs. What is the reason for the market transaction?

First, because there are diminishing returns "management", when the organization (enterprises) expanding scale, there are as follows: in the enterprise internal organization of an additional trading costs equal to that required to in normal market transactions costs, or equal to the organization by another entrepreneurs of the transaction cost, organization (enterprise) may not continue to expand. Or, when an entrepreneur fails to maximize the value of the production elements, that is, the optimal allocation of resources cannot be realized, and the organization (enterprise) may not scale again. Second, when the loss brought by resource waste is equal to the market transaction costs, or equal to the deal by another entrepreneur groups, the losses of organization (enterprises) will not continue to expand. Once again, when the organization (enterprise) organizes production, the supply price of one or more factors of production increases and the organization (enterprise) does not continue to scale up. Thus, when earnings decline, the organization (enterprise) will not continue to scale up, preferring to give it to another organization (enterprise). Similarly, when all organizations (enterprises) exist, open market transactions will exist.

Second, when some groups within the organization (enterprise) is greater than the cost of trading on the open market transaction costs, or when the organization (enterprises) do not liable to expand, is bound to exist another organization (enterprises), at the same time when another organization (enterprise) internal organization cost of production equals in the market transaction cost, which inevitably leads to the existence of market transactions.

Finally, when scale is expanding and technical constraints are limited, the increase in organizational costs and missteps of organizations will be inefficient. With different size and type of enterprise, the supply of factors of production price is different, as the spatial distribution of transactions, difference and relative price changes, such as space of different cost, transportation cost, different region strategy formulation cost and failure cost, supervision and management of the cost will increase; In particular, more space distribution and more categories are organized by an entrepreneur, and that cost will increase further. Also is so, some organizations (companies) can't wait to have a lower the cost of technology innovation, such as tend to reduce the space organization of the cost of the phone (meeting), television (meeting), and so on.

\section{Understand the Necessity of Soe Reform From The Perspective Of Government Cost}

The organization mechanism has differentiated the government mechanism. First, the administrative costs of intra-firm transactions are high. The price mechanism of resource allocation and organization (mechanism) are two ways, to a large extent, the organization (enterprise) mechanism is better than the price mechanism. The haggling of different combinations of internal production factors has been cancelled, and the entrepreneur's orders have replaced the market. But, the organization (enterprises) in the administration cost of trading resources, configuration is not necessarily, also is not always lower than through the price mechanism for the exchange cost, in this case, the enterprise the disadvantage will appear. Especially when many different activities under the control of a single organization, organization (enterprise) organization transaction cost is very high, so that in a single enterprise within the scope of any attempt to solve this problem is not possible.

Secondly, businesses are subject to various constraints. When it competes with other companies, other businesses may conduct the same activities at a lower cost, thereby binding the transaction activities and trading activities of the enterprise. At the same time, if the cost of the enterprise is too high, market transactions usually replace the internal organization of the enterprise, thus causing the enterprise to lose its meaning (i.e., bankruptcy). 
Thirdly, government administrative decision resources have many advantages. On the one hand, "the government is a super enterprise" through the use of administrative decision influence factors of production, forced to people what must do or not do, and that people must obey, to a certain extent, save the cost of many. On the other hand, the government can avoid the market entirely if needed, and the (ordinary) companies can't. An enterprise may not agree to a market agreement with the owner of the various production elements it USES. Therefore, the government has the capacity to do certain activities at a lower cost than the private sector (or at any percentage of the cost that does not exist in a particular government force).

There are also many problems in government administrative decision resources allocation. For one thing, the government's administrative machinery itself costs money, and in fact, it can sometimes be surprisingly costly. Secondly, the government's decision making and the decision of administrative decision are also regulated by the competition mechanism. At the same time, the administrative decisions made by him and the government will inevitably affect the efficiency of the operation of the economic system if there are "limitation and regional control".

Based on these considerations, direct government regulation does not necessarily result in better solutions than markets and companies. Nor can it be argued that such administrative controls will not lead to greater economic efficiency. Negative benefits, especially in some market behavior due to the many people involved, through the market and the enterprise the cost may be high, to solve the problem by the government through administrative mechanism for control group contained problem cost is high, so that you need to think of a problem and change.

\section{References}

[1] COASE.R.H (b) .The Nature of the firm, 1.origin, 2.meaning, 3.influence[J].Journal of Law, Economics and Organization, 1988, （Vol.4,no.1）:3-47

[2] COASE.R.H (b) .The Firm, the Market and the law[M].Chicago:the University of Chicago Press,1988.35-114.

[3] Bird B. J., West G. P. Time and Entrepreneurship [D]. Entrepreneurship Theory and Practice, 1997.

[4] Yu Ping He. The History and Development of the Early Entrepreneurial Theory [J]. Shanxi Finance and Economics, 2006, (8)

[5] Bull I., G. E. Willard. Towards a theory of entrepreneurship [J]. Journal of Business Venturing, 1993, 8:183-195. 